\title{
Negative life events and psychological distress and life satisfaction in U.S. college students: The moderating effects of optimism, hope, and gratitude
}

\author{
Abdi Gungor'1, Mark E. Young² and Stephen A. Sivo ${ }^{3}$ \\ ${ }^{1}$ Duzce University, Faculty of Education, Guidance and Psychological Counseling Program, Turkey (ORCID: 0000-0002-7945-0906) \\ 2 University of Central Florida, Department of Child, Family and Community Sciences, Orlando, USA (ORCID: 0000-0002-4651-9663) \\ ${ }^{3}$ University of Central Florida, Department of Learning Sciences and Educational Research, Orlando, USA (ORCID: 0000-0001-9469-4776)
}

\begin{abstract}
Negative life events are unpleasant, stressful, and uncontrollable experiences found to be risk factors for increased psychological distress and decreased life satisfaction in college students. In addition, distress and life satisfaction are closely related to college students' quality of life and academic performance. Conversely, positive psychological states have been hypothesized to buffer the effects of negative life events. Data from 738 college students in the U.S. were analyzed to examine the moderating effects of three positive psychological variables on negative life events: optimism, hope, and gratitude. The results showed that negative life events positively predicted distress and negatively predicted life satisfaction. The results also revealed that optimism, hope, and gratitude moderated the effects of negative life events. The authors conclude that the evidence supports positive psychology interventions in college counseling to combat the effects of negative life events through the positive psychological states of optimism, hope, and gratitude. The specific clinical implications for practicing counselors and educational settings are suggested.
\end{abstract}

Keywords: College students; Negative life events; Distress; Optimism; Hope; Gratitude

Article History: Submitted 14 June 2021; Revised 21 October 2021; Published online 13 November 2021

\section{Introduction}

Negative life events are unpleasant, uncontrollable, and generally stressful experiences, which cause negative changes and crucial difficulties in people's lives (Armstrong et al., 2011). They may be sudden and dramatic life-changing experiences such as job loss, which create severe psychological consequences or a global pandemic. Many college students also experience negative life events in their first away-from-home experience, including the death of grandparents, parental divorce, loss of a significant relationship, rape, social upsets, and isolation (Paladino et al., 2020). For example, the COVID-19 pandemic is having a negative impact on the mental health of college students (Copeland et al., 2020). The literature has documented the relationship between negative

\section{Address of Corresponding Author}

Abdi Gungor, PhD, Duzce University, Faculty of Education, 81620, Duzce, Turkey.

$\triangle$ abdigungor@duzce.edu.tr

How to cite: Gungor, A., Young, M. E., \& Sivo, S. A. (2021). Negative life events and psychological distress and life satisfaction in U.S. college students: The moderating effects of optimism, hope, and gratitude. Journal of Pedagogical Research, 5(4), 62-75. https://dx.doi.org/10.33902/JPR.2021472963 
life events and several psychological issues, including depressive symptoms, anxiety, somatic symptoms, delinquency, insomnia, and social dysfunction (e.g., Phillips et al., 2015). In addition, the stress resulting from the stressors can be a barrier to academic success for college students (Murff, 2005; Nelson et al., 2001).

Several research have supported the finding that general psychological distress and reduced life satisfaction are related to negative life events (e.g., Kidwai et al., 2014; Marum et al., 2014). In college students, psychological distress also predicts mental health behaviors such as alcohol consumption, unhealthy diet, physical inactivity, tobacco smoking (Deasy et al., 2014), substance abuse (Nordfjærn et al., 2010), suicidality (Campos et al., 2014), and self-injury (Martin et al., 2015). Psychological distress was also found to be a predictor of poor academic self-perception (Yamada et al., 2014) and academic procrastination (Eisenbeck et al., 2019).

The literature has concluded that negative life events are buffered by variables such as social support (Trask-Tate et al., 2010), sense of mastery (Marum et al., 2014), cognitive hardiness (Beasley et al., 2003), religious or spiritual activities (Kidwai et al., 2014), and meeting psychological needs (Rowe et al., 2013). Still, many positive psychological variables have yet to be studied (Genet \& Siemer, 2012). For this reason, we studied optimism, hope, and gratitude as potential moderators of the effects of negative life events on distress and reduced life satisfaction in college students. If it can be determined that these positive variables counteract stress in college students, it will provide support for introducing them as interventions via individual counseling, group work, and educational formats.

\subsection{The Case for Optimism}

Optimistic people can generate more positive feelings when facing difficult situations, resulting in a greater sense of well-being, whereas stressful situations produce more negative feelings in pessimistic people (Carver et al., 2011). Optimism is related to expectations (Carver \& Scheier, 2003). Optimistic people expect good things to happen when faced with difficulty, while pessimistic people expect negative outcomes (Carver et al., 2011). The essence of a positive approach to counseling and psychotherapy is not just to decrease negative feelings but to counteract them with positive ones (Frederickson, 2009).

The literature has also found optimism to be negatively related to psychological symptoms such as depression (Brissette et al., 2002; Hirsch et al., 2007), avoidant coping and negative mood (Aspinwall \& Taylor, 1992), stress (Brissette et al., 2002), psychological distress and negative religious coping (Warren et al., 2015), and suicidal ideation (Hirsch et al., 2007). On the other hand, optimism is positively related to desirable outcomes such as life satisfaction (Stanojević et al., 2014; Warren et al., 2015), self-efficacy (Stanojevic et al., 2014), social support (Brissette et al., 2002; Stanojević et al., 2014), more use of active coping (Aspinwall \& Taylor, 1992), and positive religious coping (Warren et al., 2015). In this study, we chose to consider whether or not optimism, besides increasing these positive variables, would buffer the effects of negative life events.

\subsection{Hope}

Snyder et al. (1991) proposed a definition of hope that encompasses both its cognitive and emotional aspects. Hope is defined as the ability to find ways of meeting goals and motivating self to use those methods (Snyder et al., 1991). Hope has been found to be negatively associated with various psychological concerns, including depression (Rawdin et al., 2013; Visser et al., 2013), anxiety (Michael \& Snyder, 2005), and psychological distress (Rustøen et al., 2010). The literature has also indicated positive relationships between hope and desirable states such as positive affect (Michael \& Snyder, 2005), well-being (Rawdin et al., 2013), and life satisfaction (Rustøen et al., 2010). Hope appears to reduce the effects of negative life events in depressive symptoms (Visser et al., 2013). Thus, in this study, hope was hypothesized to moderate the effects of negative life events on psychological distress. 


\subsection{Gratitude}

Gratitude is a "sense of wonder, thankfulness, and appreciation" about an unearned benefit. It can be directed interpersonally or transpersonally towards God or nature (Watkins et al., 2011). Fitzgerald (1998) considered gratitude to be an emotion and explained three components of this feeling: "(1) a warm sense of appreciation for somebody or something, (2) a sense of goodwill toward that individual or thing, and (3) a disposition to act which flows from appreciation and goodwill" (p. 120). The literature has documented that gratitude is negatively related to negative emotional outcomes such as depression, stress, and negative affect (e.g., McCullough et al., 2002; Watkins et al., 2003).

The literature has also shown a positive relationship between gratitude and positive emotions such as life satisfaction, dispositional empathy, hope, optimism, social support, and happiness (e.g., McCullough et al., 2002; Watkins et al., 2003). In an experimental study, Senf and Liau (2013) found that the gratitude intervention increased happiness and decreased depressive symptoms (Senf \& Liau, 2013). Thus, the literature suggests that gratitude is expected to moderate the effects of negative life events.

\subsection{The Present Study}

Thus far, we have asserted that negative life events have been found to be predictors of various psychological concerns and academic performance in college students (Beasley et al., 2003; Eisenbeck et al., 2019; Visser et al., 2013) and those positive psychology variables, specifically optimism, hope, and gratitude, have been identified as contributors to mental health. These three variables have been studied in the literature related to positive psychology (Carver \& Scheier, 2003; Carver et al., 2011; Snyder et al., 1991; Watkins et al., 2011). In addition, previous studies proven the effectiveness of interventions based on those variables (e.g., Rustøen et al., 2011; Thornton et al., 2014; Young \& Hutchinson, 2012). However, little is known about the effects of optimism, hope, and gratitude on the relationship between negative life events and psychological distress. Understanding this relationship could help us find ways of buffering the stress college students are experiencing. Could hope, optimism, and gratitude protect against this stress?

\section{Method}

\subsection{Research Design}

The current study was nonexperimental research using a correlational research design. "The basic design in correlational research is very simple, involving nothing more than collecting data in two or more variables for each individual in a sample and computing a correlation coefficient" (Gall et al., 2007, p. 323). Many important research in education have been conducted in correlational design, and recent studies have included more advance correlational techniques to explain relationships between several variables (Gall et al., 2007).

In the current study, the relationships between the constructs were examined in correlational aspects. The quality of a correlational study are related to the complexity of design and analytic techniques, and if the design is led by theoretical guidelines (Gall et al., 2007). The current study tested constructs through conceptual models, which were theoretically justified.

\subsection{Participants and Data Collection Procedure}

Participants were 738 undergraduate students enrolled at a large Southern university in the U.S. After obtaining Institutional Review Board (IRB) approval, and the data was collected face-to-face and online by distributing instruments to participants. The total number of students invited to the study was 938, and 775 of these students participated in the study. However, after the data cleaning procedure, the final usable data included 738 participants, yielding a $78.6 \%$ response rate.

The number of female $(\mathrm{n}=364,49.3 \%)$ and male $(\mathrm{n}=371,50.3 \%)$ participants were similar and two $(.3 \%)$ participants reported gender as other than male, female, or transgender. The age of participants ranged from 18 to $64(\mathrm{M}=21.99, \mathrm{SD}=4.19)$. Ethnicities of the participants were as 
follows: White $(\mathrm{n}=406,55 \%)$, Hispanic/Latino $(\mathrm{n}=177,24 \%)$, African American $(\mathrm{n}=56,7.6 \%)$, Asian $(\mathrm{n}=56,7.6 \%)$, American Indian/Alaska Native $(\mathrm{n}=3, .4 \%)$, Hawaiian Native/Pacific Islander $(\mathrm{n}=3, .4 \%)$, other $(\mathrm{n}=36,4.9 \%)$, with one participant $(.1 \%)$ missing data. Most participants were college juniors $(\mathrm{n}=311,42.1 \%)$, followed by seniors $(\mathrm{n}=221,29.9 \%)$, sophomores $(n=151,20.5 \%)$, freshmen $(n=33,4.5 \%)$, other $(n=20, .3 \%)$, with two $(.3 \%)$ missing data.

\subsection{Instruments}

\subsubsection{Negative life events}

The Life Experiences Survey [LES] (Sarason et al., 1978) was used to measure negative life events. The LES is a self-report instrument that includes a list of totally 60 specific events, including 10 events relevant to undergraduate students and three blank spaces for participants to write in other events. When a participant experienced an event within the last 12 months, the student rated the effect of the events from extremely negative $(-3)$ to extremely positive $(+3)$. The LES provides a total score of negative and positive life events by summing the negative and positive effects of the events, respectively. In this study, only the negative life events total score was used. To avoid any confusion, we transformed negative values of negative life events' total scores to absolute values. Thus, a higher score indicates more negative events. Because an item of the LES could be scored for both the negative life event total score or the positive life event total score, the Cronbach's alpha was not calculated in this study.

\subsubsection{Optimism}

The Life Orientation Test-Revised [LOT-R] (Scheier et al., 1994) was used to measure optimism. The LOT-R includes 10 items consisting of three positively worded items, three negatively worded items, and four filler items. The LOT-R uses a 5-point Likert scale ranging from 0 (strongly disagree) to 4 (strongly agree). The LOT-R provides a total score that is the sum of positively worded items and reversed negatively worded items. Scheier et al. (1994) reported Chronbach's alpha of .78. In this study, Chronbach's alpha was found to be .81, which indicated an acceptable level of reliability (Pallant, 2010).

\subsubsection{Hope}

The Adult Dispositional Hope Scale [ADHS] (Snyder et al., 1991) was used to measure the trait hope. The ADHS includes 12 items, four items on the agency subscale (goal-directed energy), four items on the pathways subscale (planning to meet goals), and four filler questions. Participants were asked to rate each item on a 4-point scale from 1 (definitely false) to 4 (definitely true). Even though the ADHS can provide a total score and scores for both subscales, we only used the total scores in this study. Snyder et al. (1991) reported Cronbach's alphas ranging from .74 to .84 for the total score. Cronbach's alpha for ADHS total score in this study was .78, which indicated an acceptable level of internal consistency (Pallant, 2010).

\subsubsection{Gratitude}

The Gratitude Questionnaire-6 [GQ-6] (McCullough et al., 2002) was used to measure this variable. The GQ-6 assesses individuals' experiences and expressions of appreciation and thankfulness in daily life. The GQ-6 includes six items on a 7-point Likert scale ranging from 1 (strongly disagree) to 7 (strongly agree). The GQ-6 provides a total score, with higher scores indicating higher levels of gratitude (McCullough et al., 2002). McCullough et al. (2002) reported the internal consistency of the GQ-6 to be .82. In the current study, Cronbach's alpha internal consistency for the GQ-6 was .78, an acceptable internal consistency level (Pallant, 2010).

\subsubsection{Psychological distress}

The Kessler Psychological Distress Scale [K10] (Kessler et al., 2002) was the measure of psychological distress in this study. The K-10 has 10 items assessing symptoms experienced within 
the previous 28 days (4 weeks). Items were scored using a 5-point Likert scale ranging from 1 (none of the time) to 5 (all of the time). The K-10 provides a total score ranging from 10 to 50 , where higher scores indicate a higher level of general psychological distress. Kessler et al. (2002) reported a strong internal consistency for K-10 $(a=.93)$. In this study, Cronbach's alpha was calculated at 89 .

\subsubsection{Life satisfaction}

We used the Satisfaction with Life Scale [SWLS] (Diener et al., 1985) to measure participants' levels of life satisfaction. The SWLS has five positively worded items, which are scored from 1 (strongly disagree) to 7 (strongly agree). The SWLS provides a total score ranging from five to 35, where higher scores indicate more satisfaction with one's life. Diener et al. (1985) reported that the coefficient alpha was .87 , and the test-retest correlation coefficient was .82. Cronbach's alpha was .85 in this study, indicating a good level of internal consistency (Pallant, 2010).

\subsection{Data Analysis}

All data were analyzed using Statistical Package for Social Sciences (SPSS, Version 22) for descriptive statistics, Statistical Analysis System (SAS, Version 94) for confirmatory factor analyses (CFA), and Mplus (Version 7) for the structural models. An alpha level of .05 was set to ensure a 95\% confidence level. We used structural equation modeling (SEM) to test the research questions. SEM explains the relationships between multiple variables and provides a quantitative test of a theoretical model (Schumacker \& Lomax, 2010). O'Rourke and Hatcher (2013) identified two steps for SEM: (a) developing a measurement model using CFA and (b) developing and testing a theoretical model. Therefore, we first conducted CFAs for each latent variable and tested the overall measurement model. However, since any item of the LES can load on positive or negative subscales depending on participants' perception, we included negative life event total scores as a manifest variable into all models.

Then, we tested the direct effects of negative life event scores on distress and life satisfaction using an SEM model. To determine the overall goodness of fit for CFA and SEM analyses, we used the following indices: (a) Standardized Root Mean Square Residual (SRMR, <.06) as one absolute index, (b) Comparative Fit Index (CFI, > .94) as an incremental index, and (c) Root Mean Square Error of Approximation (RMSEA, <.06) as a parsimony index (Hu \& Bentler, 1999; O'Rourke \& Hatcher, 2013).

Two models (the main effect and interaction models) for each moderator were estimated to test the moderation effects of optimism, hope, and gratitude on the effects of negative life events. The difference between the interaction and main effect models explains the effects of moderation (Maslowsky et al., 2014). To determine the relative fit of the interaction model (model 1) to the main effect model (model 0), we implemented the following formula (Maslowsky et al., 2014):

$D=-2$ [(log-likelihood for Model 0) - (log-likelihood for Model 1)]

\section{Results}

We conducted a data screening procedure to check the accuracy, missing values, and potential outliers to determine if the data was properly analyzed. First, missing data analysis showed that missing values in the data set were random (Little's MCAR test: $x^{2}=9.28, d f=6, p=.158$ ). However, we removed eight cases when more than $50 \%$ of the measurements for that case contained missing information. In addition, we detected 29 outliers by examining standardized scores ( $z$ scores) and removed them from the analyses. Overall, the total reduction after the data cleaning procedure was less than $5 \%$. Means, standard deviations, and bivariate correlations among study variables are presented in Table 1. 
Table 1

Means, Standard Deviations, and Bivariate Correlations

\begin{tabular}{lcccccccc}
\hline & $M$ & $S D$ & LESNeg & LOT-R & ADHS & GQ-6 & K10 & SWLS \\
\hline LESNeg & 8.48 & 8.41 & 1 & & & & & \\
LOT-R & 15.32 & 4.23 & $-.176^{* *}$ & 1 & & & & \\
ADHS & 25.60 & 2.95 & -.053 & $.455^{* *}$ & 1 & & & \\
GQ-6 & 36.24 & 4.74 & -.064 & $.423^{* *}$ & $.432^{* *}$ & 1 & & \\
K10 & 20.19 & 7.05 & $.352^{* *}$ & $-.492^{* *}$ & $-.289^{* *}$ & $-.294^{* *}$ & 1 & \\
SWLS & 24.93 & 6.03 & $-.266^{* *}$ & $.442^{* *}$ & $.461^{* *}$ & $.454^{* *}$ & $-.428^{* *}$ & 1 \\
\hline
\end{tabular}

Note. LESNeg: Negative life events total score; LOT-R: Optimism; ADHS: Hope; GQ-6: Gratitude; K10: Psychological distress; SWLS: Life satisfaction

** $p<.01$

\subsection{Evaluation Measurement Models}

We first tested the measurement models of study variables, except negative life events, using CFA. We tested the theoretical measurement models of each variable, but no theoretical model reached the fit results criterion. Therefore, we modified the models based on the modification indices and theoretical justifications by freeing identified errors. Fit results of the theoretical and modified model of each variable and the overall measurement model are shown in Table 2. The results showed that modified models of each variable were verified.

Table 2

Model Fit Indices of Measurement Models

\begin{tabular}{|c|c|c|c|c|c|}
\hline & Chi-square & $D F$ & SRMR & CFI & RMSEA \\
\hline \multicolumn{6}{|l|}{ LOT-R } \\
\hline Theoretical Model & 118.908 & 9 & .058 & .905 & .134 \\
\hline Modified Model & 15.233 & 5 & .022 & .991 & .056 \\
\hline \multicolumn{6}{|l|}{ ADHS } \\
\hline Theoretical Model & 162.091 & 20 & .063 & .877 & .102 \\
\hline Modified Model & 79.613 & 18 & .042 & .947 & .070 \\
\hline \multicolumn{6}{|l|}{ GQ-6 } \\
\hline Theoretical Model & 181.622 & 9 & .075 & .877 & .167 \\
\hline Modified Model & 15.549 & 7 & .021 & .994 & .042 \\
\hline \multicolumn{6}{|l|}{ K10 } \\
\hline Theoretical Model & 706.030 & 35 & .087 & .811 & .167 \\
\hline Modified Model & 132.167 & 29 & .039 & .971 & .072 \\
\hline \multicolumn{6}{|l|}{ SWLS } \\
\hline Theoretical Model & 34.354 & 5 & .027 & .980 & .093 \\
\hline Modified Model & 8.716 & 4 & .013 & .997 & .041 \\
\hline $\begin{array}{l}\text { Overall Measurement } \\
\text { Model }\end{array}$ & 1093.4628 & 531 & .050 & .944 & .039 \\
\hline
\end{tabular}

Note. LOT-R: Optimism; ADHS: Hope; GQ-6: Gratitude; K10: Psychological distress; SWLS: Life satisfaction

\subsection{Testing the Direct Effects of Negative Life Events on Psychological Distress and Life Satisfaction}

The results of the estimated structural model revealed a good fit for this data $($ Chi-square $=5915.466 ; d f=120 ;$ SRMR $=.039, \mathrm{CFI}=.966, \mathrm{RMSEA}=.053)$. The paths between negative life events and psychological distress and life satisfaction were all statistically significant $(p=.00$ for both). The participants' negative life events scores accounted for $14 \%$ of the variance explained in their psychological distress and $8 \%$ of their life satisfaction scores (see Figure 1). In 
other words, as expected, higher levels of negative life events contributed to higher levels of psychological distress and lower levels of life satisfaction.

Figure 1

Structural Model of Direct Effects

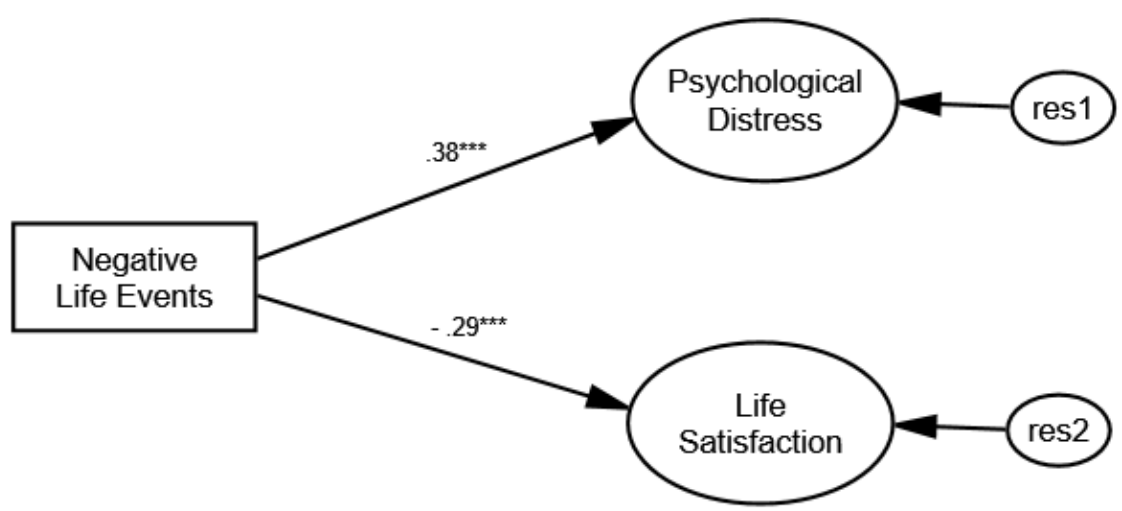

Note. ${ }^{* * *} \mathrm{p}<.001$. All presented effects are standardized.

\subsection{Testing Moderating of Optimism, Hope, and Gratitude}

When testing the moderating effect of optimism, the optimism main effect model provided a good fit with this data (SRMR $=.052, \mathrm{CFI}=.956$, RMSEA $=.048)$. Log-likelihood ratio test comparing the log-likelihood values of the main and the interaction models for optimism was 11.25 for two free parameters, indicating a significant improvement. Results showed that optimism moderated negative life events' prediction of psychological distress, but not life satisfaction. The results revealed that there was a stronger association between negative life events and psychological distress with low levels of optimism than with high levels of optimism (See Figure 2A).

Regarding the moderating effects of hope, the hope main effect model provided a good fit with these data $($ SRMR $=.046, \mathrm{CFI}=.939, \mathrm{RMSEA}=.050)$. Log-likelihood ratio test revealed a significant improvement from the main effect to interaction model (the difference was 19.46, $p<.005$ ), which refers to a significant interactional role. Hope significantly moderated negative life events' prediction of psychological distress, but not life satisfaction. The results indicated that there was a stronger association between negative life events and psychological distress for those with low levels of hope than for participants with high levels of hope (See Figure 2B)

With respect to the moderating influence of gratitude, the gratitude main effect model provided a good fit with these data $($ SRMR $=.045, \mathrm{CFI}=.962$, RMSEA $=.045)$. Log-likelihood ratio test revealed a significant moderation effect (the difference was 13.39, $p<.005$ ). The interaction between gratitude and negative life events significantly predicted psychological distress but not life satisfaction (see Table 3). The results indicated a stronger association between negative life events and psychological distress when gratitude levels are low than when they are high (See Figure 2C).

\section{Discussion}

This study examined the relationship between negative life events and psychological distress and life satisfaction in college students. In addition, this study investigated the moderating effects of optimism, hope, and gratitude on negative life events' prediction of psychological distress and life satisfaction. The results revealed that negative life events positively predicted psychological distress and negatively predicted life satisfaction, consistent with previous literature showing a relationship between negative life events and psychological distress (Marum et al., 2014).

Even though correlational studies do not allow us to make strong conclusions about cause-andeffect relationships (Gall et al., 2007), it makes a theoretical sense that higher negative life events 
Table 3

Unstandardized Coefficients between Variables in the Main Effect Models and the Interaction Models

\begin{tabular}{|c|c|c|c|}
\hline & Models & Paths & $\begin{array}{l}\text { Unstandardized } \\
\text { Coefficients }\end{array}$ \\
\hline \multirow{10}{*}{$\begin{array}{l}\text { Optimism } \\
\text { moderating }\end{array}$} & \multirow{4}{*}{$\begin{array}{l}\text { Optimism Main } \\
\text { effect model }\end{array}$} & Optimism $\rightarrow$ distress & $-.66^{* * *}$ \\
\hline & & Optimism $\rightarrow$ life satisfaction & $.53^{* * *}$ \\
\hline & & Negative life events $\rightarrow$ distress & $.04^{* * *}$ \\
\hline & & Negative life events $\rightarrow$ life satisfaction & $-.03^{* * *}$ \\
\hline & \multirow{6}{*}{$\begin{array}{c}\text { Optimism } \\
\text { Interaction model }\end{array}$} & Optimism $\rightarrow$ distress & $-.51^{* * *}$ \\
\hline & & Optimism $\rightarrow$ life satisfaction & $.49^{* * *}$ \\
\hline & & Negative life events $\rightarrow$ distress & $.04^{* * *}$ \\
\hline & & Negative life events $\rightarrow$ life satisfaction & $-.03^{* * *}$ \\
\hline & & The Interaction $\rightarrow$ distress & $-.02^{*}$ \\
\hline & & The Interaction $\rightarrow$ life satisfaction & .00 \\
\hline \multirow{10}{*}{$\begin{array}{c}\text { Hope } \\
\text { moderating }\end{array}$} & \multirow{4}{*}{$\begin{array}{c}\text { Hope Main effect } \\
\text { model }\end{array}$} & Hope $\rightarrow$ distress & $-.43^{* * *}$ \\
\hline & & Hope $\rightarrow$ life satisfaction & $.71^{* * *}$ \\
\hline & & Negative life events $\rightarrow$ distress & $.05^{\star * *}$ \\
\hline & & Negative life events $\rightarrow$ life satisfaction & $-.04^{* * *}$ \\
\hline & \multirow{6}{*}{$\begin{array}{c}\text { Hope Interaction } \\
\text { model }\end{array}$} & Hope $\rightarrow$ distress & $-.22^{* * *}$ \\
\hline & & Hope $\rightarrow$ life satisfaction & $.62^{* * *}$ \\
\hline & & Negative life events $\rightarrow$ distress & $.06^{* * *}$ \\
\hline & & Negative life events $\rightarrow$ life satisfaction & $-.04^{* * *}$ \\
\hline & & The Interaction $\rightarrow$ distress & $.06^{* * *}$ \\
\hline & & The Interaction $\rightarrow$ life satisfaction & .01 \\
\hline \multirow{10}{*}{$\begin{array}{l}\text { Gratitude } \\
\text { moderating }\end{array}$} & \multirow{4}{*}{$\begin{array}{l}\text { Gratitude Main } \\
\text { effect model }\end{array}$} & Gratitude $\rightarrow$ distress & $-.39^{* * *}$ \\
\hline & & Gratitude $\rightarrow$ life satisfaction & $.67^{* * *}$ \\
\hline & & Negative life events $\rightarrow$ distress & $.05^{\star * *}$ \\
\hline & & Negative life events $\rightarrow$ life satisfaction & $-.04^{* * *}$ \\
\hline & \multirow{6}{*}{$\begin{array}{c}\text { Gratitude } \\
\text { Interaction model }\end{array}$} & Gratitude $\rightarrow$ distress & $-.24^{* *}$ \\
\hline & & Gratitude $\rightarrow$ life satisfaction & $.66^{* * *}$ \\
\hline & & Negative life events $\rightarrow$ distress & $.05^{* * *}$ \\
\hline & & Negative life events $\rightarrow$ life satisfaction & $-.04^{* * *}$ \\
\hline & & The Interaction $\rightarrow$ distress & $-.02^{*}$ \\
\hline & & The Interaction $\rightarrow$ life satisfaction & .00 \\
\hline
\end{tabular}

Note. ${ }^{*} p<.05 .{ }^{* *} p<.01 .{ }^{* * *} p<.001$.

lead to more psychological distress and less life satisfaction. Therefore, it can be concluded that the results of this study confirmed that negative life events such as the global pandemic of the coronavirus are a hazard for psychological health, well-being, and school interest in college students (Chi et al., 2020; Güngör et al., 2020; Yang et al., 2020).

This study also examined the buffering effects of optimism, hope, and gratitude on the effects of negative life events on psychological distress and life satisfaction. The findings revealed that optimism moderated negative life events' prediction of psychological distress. Thus, an individual with a higher level of optimism had less psychological distress despite experiencing negative life events. Previous literature found that optimism moderated the effects of negative experiences on mental health (Lai, 2009), as well as suicidal ideation and suicide attempts (Hirsch et al., 2007). Similarly, Chang (1998) found that optimism moderated the effects of stress on depressive symptoms, and Tucker et al. (2013) found the significant moderating role of optimism on the association between rumination and suicide. Therefore, the findings of this study are consistent with previous research, which showed buffering effects of optimism on undesirable psychological outcomes. 
Figure 2

Optimism, hope and gratitude buffers the relationship between negative life events and psychological distress.

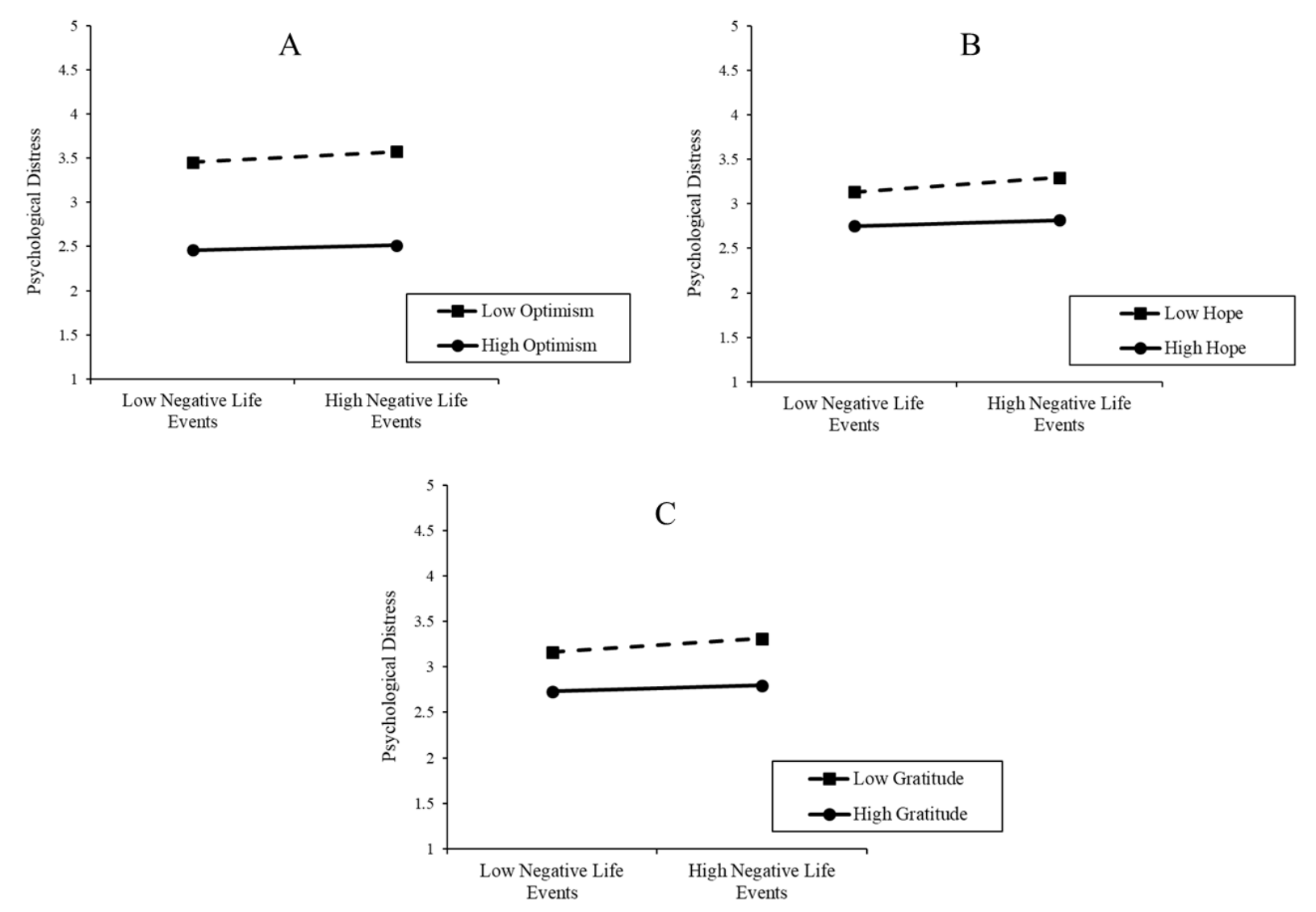

Regarding moderating of hope, results showed that the relationship between negative life events and psychological distress was weaker when levels of hope were higher. Tucker et al. (2013) found that hope moderated the relationship between rumination and suicidal ideation. In another study, hope moderated the effects of negative life events on depressive symptoms (Visser et al., 2013). In addition, Horton and Wallander (2001) found that hope lessened the effects stress level of mothers of children with chronic physical conditions on their distress. Hope was also a significant moderator between avoidant coping and general psychological distress (Glass et al., 2009). Overall, the findings of previous studies, which showed moderating effects of hope on variables such as negative life events, were supported by the results of this study.

One finding of this study was that gratitude moderated the ability of negative life events to predict psychological distress. The literature has shown the negative relationship between gratitude and undesirable outcomes such as depression, stress, negative affectivity (e.g., McCullough et al., 2002; Watkins et al., 2003). However, to our knowledge, no studies have examined the buffering effects of gratitude on psychological distress associated with negative life events. This may be important in understanding the function of gratitude in coping and prevention. Participants with greater gratitude had significantly weaker levels of psychological distress than those with low levels of gratitude for both high and low levels of negative life events.

Overall, optimism, hope, and gratitude buffered the effects of negative life events on psychological distress. The purpose of coping is to reduce undesirable emotions (Snyder, 1999). Thus, we propose that optimism, hope, and gratitude show potential for assisting college students in coping with negative life events. On the other hand, optimism, hope, and gratitude did not moderate the effects of negative life events on life satisfaction. Findings regarding moderating 
effects of these variables for life satisfaction were contradictory. For example, Chang (1998) found that optimism moderated the effects of stress on life satisfaction. However, Chen et al. (2016) found that optimism did not moderate the impacts of socioeconomic status and self-esteem on life satisfaction.

Regarding hope, no studies could be found that examined the moderating effects of hope on negative life events' predictions of life satisfaction. Concerning the moderating of gratitude, Roberts et al. (2015) found that gratitude did not moderate the relationship between materialism and life satisfaction. Even though in this study and the literature, overall, these variables have been found as a moderator between predictor variables and negative outcome variables (e.g., psychological distress), we did not find them as significant moderators on life satisfaction, as logically consistent with Chen et al. (2016) and Roberts et al. (2015). Trait theory argues that "there is an element of stability in people's levels of well-being that cannot be explained by the stability of the conditions of people's lives, and that subjective well-being is strongly influenced by stable personality disposition" (Diener et al., 2011; p.189). Hence, it can be argued that optimism, hope, and gratitude did not lessen the effect of negative life events on life satisfaction because life satisfaction tends to be stable and not easily influenced by changeable life conditions. Nevertheless, the results showed that optimism, hope, and gratitude are still directly related to life satisfaction. Thus, we can conclude that even though the hope, optimism, and gratitude did not buffer the effects of negative life events, which are based on changeable life conditions, their direct stable effects can be positive on life satisfaction.

\section{Implications for College Counselors and Administrations}

Although college life is often depicted as one of the best times in life, it can also be the first early experiences of loss and trauma. For instance, besides the health risks associated with COVID-19, they may be required to attend distance education, are experiencing financial problems, cut off from social support of friends and family, and feeling a loss of interest in school. Therefore, college counselors should be aware that collecting information about such life issues, even those which are not considered trauma, can help understand the roots of clients' problems.

The main implication of the current study is that positive psychological variables can help college students combat the usual stresses of college life and the unique stress of this pandemic era. The literature contains guidance for developing psychoeducational and in-session techniques for increasing optimism, hope, and gratitude (e.g., Parks \& Schueller, 2014). Carver et al. (2011) have identified cognitive-behavioral therapies and techniques can be helpful for clients to enhance optimism. Other authors have recommended programs to enhance hope (e.g., HOPE-IN by Rustøen et al., 2011; Mindfulness Hope Therapy by Thornton et al., 2014). Young and Hutchinson (2012) suggested that counselors recognize that "there is sufficient evidence to recommend the use of gratitude-based interventions" (p. 109). Similarly, Senf and Liau (2013) found the effectiveness of the gratitude-based intervention. Participants were asked to write a letter to someone they feel grateful to and have never thanked. In another experimental study, Rash et al. (2011) tested the effectiveness of a 4-week gratitude contemplation intervention program on well-being among 56 adults.

Murff (2005) pointed out that effective coping strategies are necessary for college students to continue their professional workforce (Murff, 2005). Thus, counseling and educational practices that potentially increase optimism, hope, and gratitude would also help college students overcome stress and eventually increase academic and professional performance. In addition to counselingrelated individual and group interventions, college administrations could include courses to enhance positive psychology variables into the curriculum. Also, techniques or interventions for optimism, hope, and gratitude can be included in counselor education programs, as a course or as a part of a course. Therefore, students can be better prepared to help clients cope with life events. Similarly, positive psychology in school settings has been discussed and suggested in the literature (Güngör, 2017; Seligman et al. 2009). 


\section{Limitations and Directions for Future Research}

The major limitation of this study was its correlational approach which tested relationships between variables from a set of data. The results revealed relationships between negative life events and psychological distress and life satisfaction, but it is not possible to make firm conclusions about causality. Another limitation was stem from the sampling method (criteria sampling). The target population of this study was undergraduate students in the U.S., and the accessible population was a large university in the Southeastern U.S. Therefore, the results should be considered in this light. Another limitation was the instrumentation. Because each item can measure each event as either positive or negative in the LES, the internal reliability of the negative life event score could not be calculated. Thus, the limitation is due to the lack of information concerning the reliability and validity of the LES. All the instruments in the study suffer from the limitation that they are self-report.

Future studies designed as longitudinal and experimental should address the relationship between negative life events and psychological distress and life satisfaction to help draw more definitive conclusions about causality. For example, the next logical step is to conduct experimental studies with college students, focusing on utilizing these positive psychology variables to improve coping and enhance life satisfaction. In addition, how optimism, hope, and gratitude help individuals cope. Thus, future qualitative studies will be helpful to understand these dynamics better. Despite these needs for future investigation, the authors recommend incorporating targeted psychoeducational programs to groups of college students and further training for college counseling in helping clients enhance positive psychological states to combat the effects of negative life events.

Acknowledgements. This study was submitted as the first author's dissertation for the degree of Doctor of Philosophy in the College of Education and Human Performance at the University of Central Florida under the supervision of Mark E. Young (second author) and Stephen A. Sivo (third author) in August 2016.

This study was orally presented by the first author at 2nd Eurasian Congress of Positive Psychology held in Istanbul between May 12th to 14th, 2017.

\section{References}

Armstrong, A. R., Galligan, R. F., \& Critchley, C. R. (2011). Emotional intelligence and psychological resilience to negative life events. Personality and Individual Differences, 51(3), 331-336. https://doi.org/10.1016/j.paid.2011.03.025

Aspinwall, L. G., \& Taylor, S. E. (1992). Modeling cognitive adaptation: A longitudinal investigation of the impact of individual differences and coping on college adjustment and performance. Journal of personality and social psychology, 63(6), 989-1003. https://doi.org/10.1037/0022-3514.63.6.989

Beasley, M., Thompson, T., \& Davidson, J. (2003). Resilience in response to life stress: The effects of coping style and cognitive hardiness. Personality and Individual Differences, 34(1), 77-95. https://doi.org/10.1016/S0191-8869(02)00027-2

Brissette, I., Scheier, M. F., \& Carver, C. S. (2002). The role of optimism in social network development, coping, and psychological adjustment during a life transition. Journal of personality and social psychology, 82(1), 102-111. https:// doi.org/10.1037/0022-3514.82.1.102

Campos, R. C., Besser, A., Abreu, H., Parreira, T., \& Blatt, S. J. (2014). Personality vulnerabilities in adolescent suicidality: The mediating role of psychological distress. Bulletin of The Menninger Clinic, 78(2), 115-139. https://doi.org/10.1521/bumc.2014.78.2.115

Carver, C. S., \& Scheier, M. (2003). Optimism. In S. J. Lopez \& C. R. Snyder (Eds.). Positive psychological assessment: A handbook of models and measures (pp. 75-89). American Psychological Association.

Carver, C. S., Scheier, M. F., Miller, C. J., \& Fulford, D. (2011). Optimism. In S. J. Lopez \& C. R. Snyder (Eds.), Oxford handbook of positive psychology (2nd ed., pp. 303-311). Oxford University Press. 
Chang, E. C. (1998). Does dispositional optimism moderate the relation between perceived stress and psychological well-being?: A preliminary investigation. Personality and Individual Differences, 25(2), 233240. https:// doi.org/10.1016/S0191-8869(98)00028-2

Chen, W., Niu, G. F., Zhang, D. J., Fan, C. Y., Tian, Y., \& Zhou, Z. K. (2016). Socioeconomic status and life satisfaction in Chinese adolescents: Analysis of self-esteem as a mediator and optimism as a moderator. Personality and Individual Differences, 95, 105-109. https://doi.org/10.1016/j.paid.2016.01.036

Chi, X., Becker, B., Yu, Q., Willeit, P., Jiao, C., Huang, L., Hossain, M. M., Grabovac, I., Yeung, A., Lin, J., Veronese, N., Wang, J., Zhou, X., Doig, S. R., Liu, X., Carvalho, A. F., Yang, L., Xiao, T., Zou, L., ... Solmi, M. (2020). Prevalence and psychosocial correlates of mental health outcomes among Chinese college students during the coronavirus disease (COVID-19) pandemic. Frontiers in Psychiatry, 11, 803. https://doi.org/fpsz

Copeland, W. E., McGinnis, E., Bai, Y., Adams, Z., Nardone, H., Devadanam, V., Rettew, J., \& Hudziak, J. J. (2020). Impact of COVID on college student mental health and wellness. Journal of the American Academy of Child \& Adolescent Psychiatry, 60(1), 134-141. https:// doi.org/10.1016/j.jaac.2020.08.466

Deasy, C., Coughlan, B., Pironom, J., Jourdan, D., \& Mcnamara, P. M. (2014). Psychological distress and lifestyle of students: Implications for health promotion. Health Promotion International, 30(1), 77-87. https://doi.org/10.1093/heapro/dau086

Diener, E. D., Emmons, R. A., Larsen, R. J., \& Griffin, S. (1985). The satisfaction with life scale. Journal of personality assessment, 49(1), 71-75. https://doi.org/10.1207/s15327752jpa4901_13

Diener, E., Oishi, S., \& Lucas, R. E. (2011). Subjective well-being: The science of happiness and life satisfaction In S. J. Lopez \& C. R. Snyder (Eds.), Oxford handbook of positive psychology (2nd ed., pp. 187194). Oxford University Press.

Eisenbeck, N., Carreno, D. F., \& Uclés-Juárez, R. (2019). From psychological distress to academic procrastination: Exploring the role of psychological inflexibility. Journal of Contextual Behavioral Science, 13, 103-108. https:// doi.org/10.1016/j.jcbs.2019.07.007

Fitzgerald, P. (1998). Gratitude and justice. Ethics, 109(1), 119-153. https:/ / doi.org/10.1086/233876

Frederickson, B. (2009). Positivity. Crown Publishers.

Gall, M. D., Gall, J. P., \& Borg, W. R. (2007). Educational research: An introduction (8th ed.). Allyn \& Bacon.

Genet, J. J., \& Siemer, M. (2012). Rumination moderates the effects of daily events on negative mood: Results from a diary study. Emotion, 12(6), 1329-1339. https://doi.org/10.1037/a0028070

Glass, K., Flory, K., Hankin, B. L., Kloos, B., \& Turecki, G. (2009). Are coping strategies, social support, and hope associated with psychological distress among Hurricane Katrina survivors?. Journal of Social and Clinical Psychology, 28(6), 779-795. https://doi.org/10.1521/jscp.2009.28.6.779

Güngör, A. (2017). Eğitimde pozitif psikolojiyi anlamak [Understanding positive psychology in education]. The Journal of Turkish Educational Sciences, 15(2), 154-166.

Güngör, A., Karaman, M. A., Sari, H. İ., \& Çolak, T. S. Investigating the factors related to coronavirus disease 2019 (covid-19) on undergraduate students' interests in coursework. International Journal of Psychology and Educational Studies, 7(3), 1-13. https://doi.org/10.17220/ijpes.2020.03.001

Hirsch, J. K., Wolford, K., LaLonde, S. M., Brunk, L., \& Morris, A. P. (2007). Dispositional optimism as a moderator of the relationship between negative life events and suicide ideation and attempts. Cognitive Therapy \& Research, 31(4), 533-546. https:// doi.org/10.1007/s10608-007-9151-0

Horton, T. V., \& Wallander, J. L. (2001). Hope and social support as resilience factors against psychological distress of mothers who care for children with chronic physical conditions. Rehabilitation Psychology, 46(4), 382-399. https:// doi.org/10.1037/0090-5550.46.4.382

Hu, L., \& Bentler, P. M. (1999). Cutoff criteria for fit indexes in covariance structure analysis: conventional criteria versus new alternatives. Structural Equation Modeling, 6(1), 1-55. https://doi.org/10.1080/10705519909540118

Kessler, R. C., Andrews, G., Colpe, L. J., Hiripi, E., Mroczek, D. K., Normand, S. L. T., Walters, E. E., \& Zaslavsky, A. M. (2002). Short screening scales to monitor population prevalences and trends in nonspecific psychological distress. Psychological medicine, 32(6), 959-976. https://doi.org/10.1017/S0033291702006074

Kidwai, R., Mancha, B., Brown, Q., \& Eaton, W. (2014). The effect of spirituality and religious attendance on the relationship between psychological distress and negative life events. Social Psychiatry \& Psychiatric Epidemiology, 49(3), 487-497. https://doi.org/10.1007/s00127-013-0723-x 
Lai, J. C. (2009). Dispositional optimism buffers the impact of daily hassles on mental health in Chinese

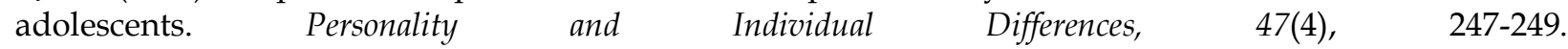
https://doi.org/10.1016/j.paid.2009.03.007

Martin, G., Thomas, H., Andrews, T., Hasking, P., \& Scott, J. G. (2015). Psychotic experiences and psychological distress predict contemporaneous and future non-suicidal self-injury and suicide attempts in a sample of Australian school-based adolescents. Psychological Medicine, 45(2), 429-437. https://doi.org/10.1017/S0033291714001615

Marum, G., Clench-Aas, J., Nes, R., \& Raanaas, R. (2014). The relationship between negative life events, psychological distress and life satisfaction: a population-based study. Quality of Life Research, 23(2), 601611. https://doi.org/10.1007/s11136-013-0512-8

Maslowsky, J., Jager, J., \& Hemken, D. (2014). Estimating and interpreting latent variable interactions A tutorial for applying the latent moderated structural equations method. International journal of behavioral development, 39(1), 1-10. https:// doi.org/10.1177/0165025414552301

McCullough, M. E., Emmons, R. A., \& Tsang, J. (2002). The grateful disposition: A conceptual and empirical topography. Journal of Personality and Social Psychology, 82(1), 112-127. https://doi.org/10.1037/00223514.82.1.112

Michael, S. T., \& Snyder, C. R. (2005). Getting unstuck: The roles of hope, finding meaning, and rumination in the adjustment to bereavement among college students. Death studies, 29(5), 435-458. https://doi.org/10.1080/07481180590932544

Murff, S. H. (2005). The impact of stress on academic success in college students. The ABNF Journal, 16(5), 102-104.

Nelson, N. G., Dell'Oliver, C., Koch, C., \& Buckler, R. (2001). Stress, coping, and success among graduate $\begin{array}{lllll}\text { students in clinical psychology. Psychological reports, } & 88(3), & \text { 759-767. }\end{array}$ https://doi.org/10.2466/pr0.2001.88.3.759

Nordfjærn, T., Hole, R., \& Rundmo, T. (2010). Interrelations between patients' personal life events, psychosocial distress, and substance use. Substance Use $\mathcal{E}$ Misuse, 45(7/8), 1161-1179. https://doi.org/10.3109/10826080903567863

O'Rourke, N., \& Hatcher, L. (2013). A step-by-step approach to using SAS for factor analysis and structural equation modeling (2nd ed.). SAS Institute.

Paladino, D. A., Gonzalez, L. M., \& Watson, J. C. (2020). College counseling and student development: Theory, practice and campus collaboration. Wiley.

Pallant, J. (2010). SPSS Survival Manual (4th ed.). McGraw Hill.

Parks, A. C., \& Schueller, S. (Eds.). (2014). The Wiley Blackwell handbook of positive psychological interventions. Wiley.

Phillips, A. C., Carroll, D., \& Der, G. (2015). Negative life events and symptoms of depression and anxiety: stress causation and/or stress generation. Anxiety, Stress $\mathcal{E}$ Coping, 28(4), 357-371. https:// doi.org/10.1080/10615806.2015.1005078

Rash, J. A., Matsuba, M. K., \& Prkachin, K. M. (2011). Gratitude and Well-Being: Who Benefits the Most from a Gratitude Intervention?. Applied Psychology: Health and Well- Being, 3(3), 350-369. https://doi.org/10.1111/j.1758-0854.2011.01058.x

Rawdin, B., Evans, C., \& Rabow, M. W. (2013). The relationships among hope, pain, psychological distress, and spiritual well-being in oncology outpatients. Journal of Palliative Medicine, 16(2), 167-172. https://doi.org/10.1089/jpm.2012.0223

Roberts, J. A., Tsang, J. A., \& Manolis, C. (2015). Looking for happiness in all the wrong places: The moderating role of gratitude and affect in the materialism-life satisfaction relationship. The Journal of Positive Psychology, 10(6), 489-498. https:// doi.org/10.1080/17439760.2015.1004553

Rowe, C. A., Walker, K. L., Britton, P. C., \& Hirsch, J. K. (2013). The relationship between negative life events and suicidal behavior: Moderating role of basic psychological needs. Crisis: The Journal of Crisis Intervention and Suicide Prevention, 34(4), 233-241. https://doi.org/10.1027/0227-5910/a000173

Rustøen, T., Cooper, B. A., \& Miaskowski, C. (2010). The importance of hope as a mediator of psychological distress and life satisfaction in a community sample of cancer patients. Cancer Nursing, 33(4), 258-267. https://doi.org/10.1097/NCC.0b013e3181d6fb61

Rustøen, T., Cooper, B. A., \& Miaskowski, C. (2011). A longitudinal study of the effects of a hope intervention on levels of hope and psychological distress in a community-based sample of oncology patients. European Journal of Oncology Nursing, 15(4), 351-357. https://doi.org/10.1016/j.ejon.2010.09.001 
Sarason, I. G., Johnson, J. H., \& Siegel, J. M. (1978). Assessing the impact of life changes: development of the Life Experiences Survey. Journal of Consulting and Clinical Psychology, 46(5), 932-946. https://doi.org/10.1037/0022-006X.46.5.932

Scheier, M. F., Carver, C. S., \& Bridges, M. W. (1994). Distinguishing optimism from neuroticism (and trait anxiety, self-mastery, and self-esteem): A re-evaluation of the life orientation test. Journal of Personality $\mathcal{E}$ Social Psychology, 67(6), 1063-1078.

Schumacker, R.E., \& Lomax, R. G. (2010). A beginner's guide to structural equation modeling (3ed ed.). Routledge Taylor \& Francis Group.

Seligman, M. E. P., Ernst, R. M., Gillham, J., Reivich, K., \& Linkins, M. (2009). Positive education: Positive psychology and classroom interventions. Oxford Review of Education, 35(3), 293-311. https://doi.org/10.1080/03054980902934563

Senf, K., \& Liau, A. K. (2013). The effects of positive interventions on happiness and depressive symptoms, with an examination of personality as a moderator. Journal of Happiness Studies, 14(2), 591-612. https://doi.org/10.1007/s10902-012-9344-4

Snyder, C. R. (1999). Coping: The psychology of what works. Oxford University Press.

Snyder, C., Harris, C., Anderson, J. R., Holleran, S. A., Irving, L. M., Sigmon, S. T., Yoshinobu, L., Gibb, J., Langelle, C., \& Harney, P. (1991). The will and the ways: Development and validation of an individualdifferences measure of hope. Journal of Personality and Social Psychology, 60(4), 570-585.

Stanojević, D., Krstić, M., Jaredić, B., \& Dimitrijević, B. (2014). Proactive coping as a mediator between resources and outcomes: A structural equations modeling analysis. Applied Research in Quality of Life, 9(4), 871-885. https://doi.org/10.1007/s11482-013-9274-2

Thornton, L. M., Cheavens, J. S., Heitzmann, C. A., Dorfman, C. S., Wu, S. M., \& Andersen, B. L. (2014). Test of mindfulness and hope components in a psychological intervention for women with cancer recurrence. Journal of consulting and clinical psychology, 82(6), 1087-1100. https://doi.org/10.1037/a0036959

Trask-Tate, A., Cunningham, M., \& Lang-DeGrange, L. (2010). The importance of family: The impact of social support on symptoms of psychological distress in African American girls. Research in Human Development, 7(3), 164-182. https:// doi.org/10.1080/15427609.2010.504458

Tucker, M., \& Kelley, M. (2009). Social support and life stress as related to the psychological distress of single enlisted Navy mothers. Military Psychology, 21(2), 82-97. https:// doi.org/10.1080/08995600903249198

Visser, P. L., Loess, P., Jeglic, E. L., \& Hirsch, J. K. (2013). Hope as a moderator of negative life events and depressive symptoms in a diverse sample. Stress \& Health: Journal of the International Society for the Investigation of Stress, 29(1), 82-88. https://doi.org/10.1002/smi.2433

Warren, P., Van Eck, K., Townley, G., \& Kloos, B. (2015). Relationships among religious coping, optimism, and outcomes for persons with psychiatric disabilities. Psychology of Religion and Spirituality, 7(2), 91-99. https://doi.org/10.1037/a0038346

Watkins, P. C., Gelder, M. V., \& Frias, A. (2011). Furthering the science of gratitude. In S. J. Lopez \& C. R. Snyder (Eds.), Oxford handbook of positive psychology (2nd ed., pp. 437-445). Oxford University Press.

Watkins, P. C., Woodward, K., Stone, T., \& Kolts, R. L. (2003). Gratitude and happiness: Development of a measure of gratitude, and relationships with subjective well-being. Social Behavior and Personality: An international journal, 31(5), 431-451. https:// doi.org/10.2224/sbp.2003.31.5.431

Yamada, Y., Klugar, M., Ivanova, K., \& Oborna, I. (2014). Psychological distress and academic selfperception among international medical students: the role of peer social support. BMC medical education, 14(1), 1-8. https:// doi.org/10.1186/s12909-014-0256-3

Yang, D., Tu, C. C., \& Dai, X. (2020). The effect of the 2019 novel coronavirus pandemic on college students in Wuhan. Psychological Trauma: Theory, Research, Practice, and Policy, 12(S1), 6-14. http:/ / dx.doi.org/10.1037/tra0000930

Young, M. E., \& Hutchinson, T. S. (2012). The rediscovery of gratitude: implications for counseling practice. The Journal of Humanistic Counseling, 51(1), 99-113. https:/ / doi.org/10.1002/j.2161-1939.2012.00008.x 